\title{
The Impact of Life Style and Nutritional Components in Primary Prevention of Colorectal Cancer
}

\author{
Saad Sabbar Dahham, Amin Malik Abdul Majid \\ EMAN Research and Testing Laboratory, School of Pharmaceutical Sciences, Universiti Sains Malaysia, 11800, Penang, Malaysia.
}

\section{ARTICLE INFO}

Article history:

Received on: 01/06/2016

Revised on: 05/07/2016

Accepted on: 30/07/2016

Available online: 26/09/2016

Key words:

Colorectal cancer,

prevention, lifestyle,

nutritional factors.

\begin{abstract}
Colorectal cancer (CRC) is one of the most aggressive malignant solid tumors which remain a rampant killer across the world. Toxic drugs have failed to reduce the morbidity and mortality rate of CRC patients. In addition, adoption of cancer-causing behaviors has increased the globule burden of CRC. Inappropriate lifestyle such as, smoking, obesity, physical inactivity, alcohol consumption and poor dietary components, all of which have been reported to aggravate the CRC incidence worldwide. In this regard, there is a growing awareness and increasing interest in cancer prevention approaches focusing on environmental and behavioral interventions, where specific carcinogenic factors implicated in cancer initiation, promotion, and progression may be triggered. In this communication, we report the role of lifestyle patterns and nutritional components in the modulation of $\mathrm{CRC}$, and discuss the possible biological mechanism which involves in CRC pathogenesis. The findings indicate that smoking and alcohol consumption release a wide range of carcinogenic compounds such as, polynuclear aromatic hydrocarbons and acetaldehyde which can cause DNA damage and alter the function of tumor suppressor genes. Moreover, the link between obesity and CRC has been detected in several studies, whereby obesity induces insulin resistance and hyperglycemia, resulted in NF- $\mathrm{kB}$ and IGF-1 activation. In contrast, an inverse association between physical activity and cancer incidence has been constantly observed; the risk of $\mathrm{CRC}$ has been reduced $10-60 \%$ in the regular physical activity. With respect to nutritional components, compelling evidence indicates that avoidance of high intake of processed red meat, highly refined grains, starches, sugar and salt, and replacing them with poultry, fish, unrefined grains, legumes, vegetables, and fruits are strongly associated with lower risks of CRC.
\end{abstract}

\section{INTRODUCTION}

Cancer is a group of more than 100 different diseases, arises from dysregulation of the normal cellular mechanism and alterations in the expression of multiple genes, leading to local tissue invasion and eventually metastasis (Dahham et al., 2015 a). Colorectal cancer (CRC) also known as colon cancer, is a malignant epithelial neoplastic arising from the colonic or rectal mucosa, results from a multi-step process leading to the accumulation of genetic and epigenetic alterations of bowel habits leading to uncontrolled cell growth, proliferation and tumor progression (Wells et al., 2009). The disease occurs

\footnotetext{
* Corresponding Author

Email:hawk_dijla@yahoo.com
}

sporadically in $90 \%$ of CRC cases and only $10 \%$ of the patients have a family history, suggesting the role of genes and environment in CRC development (Bogaert and Prenen, 2013). However, a series of molecular alteration have been detected during CRC development (Figure 1). The first step is inactivation of Adenomatous Polyposis Coli (APC) tumor suppressor gene (Knudson, 2001). More than 800 mutations of the APC gene have been recently described to play crucial roles in non-functional APC gene products (Zeichner et al., 2012). About $80 \%$ of CRC tumors contain inactivation mutation of APC suppressor, which is responsible for more than 600,000 deaths every year worldwide (Dow et al., 2015). The second step start with the episodic accumulation of specific mutations in RAS oncogene, in particular, activation of K-Ras mutated gene is highly presented in human tumors, with $30-50 \%$ of CRC patients. 
Activated K-Ras triggers inflammation which can promote tumor progression (Goel et al., 2015). The development of large polyp acquiring additional mutations in genes of the p53 pathway, mutant p53 loses its ability to bind DNA effectively and as a result the p21 protein will be down regulated and affect the process of cell division. In addition to the dramatic acceleration of tumor initiation and promotion which driven by APC and K-Ras mutation, P53 mutant gene enables tumor invasion and metastasis. The incidence of P53 mutation in CRC tumors accounts 54\% (Dow et al., 2015). The transition from colorectal epithelial cell to carcinoma and metastatic is usually associated with aneuploidy (chromosomal instability) due to a loss of mismatch repair function in cancer cells and rapid rate of proliferation. Whether chromosomal insatiability initiates the appropriate environments for the accumulation of these mutations or vice versa remains a prospective and unknown (Pino and Chung, 2010) All in all, these events generally take 20-40 years to occur, with systematic spontaneous mutation rate (Rajagopalan et al., 2003).Nevertheless, $90 \%$ of the cancers are linked to environmental exposure, where the specific carcinogenic agents can induce inflammation and initiate neoplasia at the single cell level which can be fixed on cell division and promoted by many signaling pathways leading to genetic abnormalities and eventually malignancies (Moore and Sobue, 2010). Furthermore, the trends of CRC mortality are driven by environmental changes and prompted by the economic transition. Environmental factors such as dietary pattern, smoking, alcohol consumption and obesity is highly associated with CRC risk. Importantly, all these risk factors are potentially modifiable and avoidable. Therefore, the main strategy for control of CRC would be through primary preventionwhich aims to reduce and obstruct the initiation step of the cancer cell. In this review, we provide an overview of the life style roles and nutritional components in the modulation of CRC, and discuss the possible biological mechanism which involve in $\mathrm{CRC}$ pathogenesis.

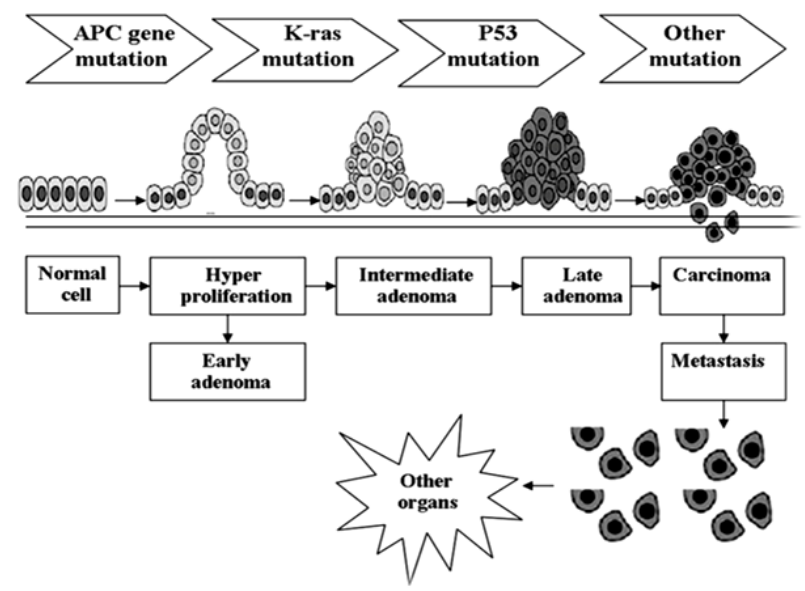

Fig. 1: A possible multi-step scenario for colorectal cancer, showing mutational events that associated with each step in the colorectal tumorgenesis process.

\section{Burden of CRC}

Globally, CRC is a major cause of mortality and morbidity, with more than 1.2 million new cases diagnosed annually. It accounts for $9.7 \%$ of all cancer cases and $8 \%$ of all cancer-related deaths (Theodoratou et al., 2014).Notwithstanding rapid development in diagnosis strategy and treatment approaches in recent decades, CRC remains the third most frequent cancer in men, after lung and prostate cancer, and is the second most frequent cancer in women following the breast cancer (López et al., 2014). Recently, The World Health Organization (WHO) estimates an increase of $77 \%$ in the number of newly diagnosed cases of CRC and raise to $80 \%$ in death cases by 2030 . Mortality and incidence rates of CRC are varied, because of geographic region, ethnic group, age, lifestyle factors and medical settings. About $60 \%$ of CRC cases are diagnosed in industrialized countries such as USA, Europe and Japan (Binefa et al., 2014). On the other hand, low incidence of CRC has been observed in East Europe, Asia, Africa, and South America. However, the incidence rate has increased in many geographical regions where it was traditionally low including: China (170000 new cases every year) (Li et al., 2015), Spain (29000 new cases every year) (López et al., 2014), Slovakia (92 per 100,000), Hungary (87 per 100,000), and the Czech Republic (81 per 100,000) (Ferlay et al., 2013). Similarly, Middle East countries that were historically considered to have low rates of CRC such as Egypt, Iran , Jordan, Saudi Arabia and Yemen has increased dramatically over the past few decades (Bishehsari et al., 2014). The growing incidence of CRC in many Asian countries has drawn the attention of Asia Pacific Working Group on CRC to initiate in 2004, from ten Asian countries including, China, India, Indonesia, Japan, South Korea Malaysia, Philippines, Singapore, Taiwan, and Thailand, to address the significant progress in increasing of CRC incidence and mortality rates (Sung et al., 2005). In Malaysia CRC recorded to be the first common cancer among the men and the second most common cancer diagnosed after the barest cancer among women, in 2006, a total of 2,866 new cases were recorded by National Cancer Registry and represent $13.2 \%$ of all cancer cases (Omar et al., 2006). Despite the rise of CRC in almost all developing countries, the acceleration rates may be driven by different environmental risk factors, which play a pivotal role in the etiology of the diseases. Thus, preventive strategies that minimize inappropriate lifestyle would significantly lower the burden of CRC worldwide.

\section{Lifestyle Factors Associated with CRC pathogenesis}

As previously mentioned, over $90 \%$ of CRC cases occurs sporadically and thus correlated with lifestyle factors. Unlike another type of cancers, CRC is a preventable disease, and it is estimated that about $75 \%$ of CRC cases could be avoided with a healthy lifestyle (Giovannucci, 2002). Additionally, there are nonmodifiable risk factors associated with the incidence of CRC such as age and hereditary factors. Those that an individual cannot control (Haggar and Boushey, 2009). However, modifiable risk factors such as poor diet, alcohol intake, smoking and being overweight may release several carcinogenic substances which can induce specific biological responses that could be responsible for the increased risk of CRC initiation, promotion, and progression as shown in Figure 2. 


\section{Dietary factors}

The strong relation between dietary pattern and CRC has been extensively examined in the last decades. According to the previous research, dietary factors were suggested to be responsible for $35 \%$ of all cancer-related deaths and $70 \%$ of CRC death cases (Anand et al., 2008), Indicating the crucial role of diets in CRC development. Since the incidence rate of CRC is very high in developed countries, it is well established that Western diet which characterized by rich animal product, fats, and sugar has directly implicated in the development of CRC (Chan and Giovannucci, 2010; Kantor and Giovannucci, 2015a; Key et al., 2004; Nesbeth et al., 2015). The Positive association between higher intake of red meat and CRC risk have been demonstrated in many epidemiological, experimental and analysis studies (Clarke and Lockett, 2014; Vargas and Thompson, 2012).A recent metaanalysis of 21 prospective large-cohort studies shows that the risk of CRC increases approximately linearly with excessive red meat intake; the risk of CRC was estimated to increase about $14 \%$ for $100 \mathrm{~g} /$ day increase of total red and processed meats (Chan et al., 2011). However, the underlying mechanism of possible increased risk of CRC with red meat intake is unclear (Martínez, 2005). Nonetheless, there are a few possible mechanisms that may clarify the ambiguity. Several studies have recently indicated that carcinogenic components such as heterocyclic amines and polycyclic aromatic hydrocarbons released during cooking meats (fried, grilled, or broiled) at high temperatures and long periods of time (Budhathoki et al., 2015; Santarelli et al., 2008; Zheng and Lee, 2009). In addition, red meat contains a high amount of heme iron which is an important toxic compound for formation of hydroxyl radical through Fenton reaction which considers the most biologically toxic oxygen species implicated in oxidative stress. Thus, heme iron may promote the initiation of tumor cells by influencing the cytoplasmic and nuclear signal transduction pathways (Bastide et al., 2011; Sosa et al., 2013). Furthermore, the effect of toxic compounds present in animal products may be mediated through the production of fat peroxidation which causes DNA damage, and thus influences the initiation, promotion, and progression of tumor stages. (Guéraud et al., 2015) Importantly, adoption of bad dietary habits will change the structure and diversity of gastrointestinal microbiota, which plays a central role in gastrointestinal immune stimulation, control of pathogenic bacteria, modulation of gastrointestinal epithelial cell proliferation and differentiation, and management of bioactive foods and chemical compounds. However, disturbance of the normal gastrointestinal microbiota will generate high levels of secondary bile acids in the bowel, which are cytotoxic to colonic epithelial cells (Akin and Tözün, 2014; Keku et al., 2015). The role of fat in CRC development remain poorly understood and controversial, on one hand, it has been suggested that high-fat diets increase the intestinal secretion of bile acids, which can be metabolized by the gut microbiota to cancer-promoting agents (Song et al., 2015), on the other hand, a meta-analysis of 13 prospective cohort studies indicated that neither total fat nor specific types of fat were associated with CRC risk (Liu et al., 2011). In addition, a recent systematic review have highlighted the positive association of preserved foods with high salt content and sugar consumption in CRC pathogenesis (Azeem et al., 2015).Finally, there is several food items are commonly consumed in our daily life may involve in CRC risk. Analysis of all these items is very complex and needs further investigation.

\section{Alcohol intake}

In general, alcohol consumption is casually associated with more than 200 diseases; in particular, alcohol intake was directly responsible to increase the net burden of cancer, liver cirrhosis and injury, which caused 1,500,000 deaths in 2010 (Rehm and Shield, 2014). However, the first report of the positive link between alcohol intake and increased the risk of cancer was documented in 1910 (Tuyns, 1979). Since then, several studies have revealed the effect of alcohol in each type of cancers. Alcohol is categorized as a carcinogenic agent by the World Health Organization (WHO) and the International agency for Research on Cancer (IARC). An association between alcohol consumption and CRC risk has been observed in several prospective cohort studies, which indicated that intake of more than 30-45 g/day of alcohol results in increased risk of CRC to 1.16-1.41, respectively (Martínez, 2005; Durko and MaleckaPanas, 2014). It is difficult to elucidate the mechanisms involved in alcohol-induced CRC development because in most cases smoking and chronic inflammation are additional risk factors in patients that drink alcohol (Haas et al., 2012). However, alcohol may increase CRC through a number of possible mechanisms, including the actions of acetaldehyde, the first and most toxic substance which oxidized from ethanol metabolism through alcohol dehydrogenase (ADH) enzymes. In addition, highly reactive oxygen (ROS) contain molecules-promoting carcinogenesis through their binding to DNA and proteins, which destroys folate and results in secondary hyperproliferation (Anand et al., 2008; Kantor and Giovannucci, 2015 b; Seitz and Becker, 2007). Moreover, inflammation may be one of the mechanisms by which alcohol affects the risk of CRC. Study findings suggest that ethanol can activate the NF- $\kappa$ Bproinflammatory pathway, which can involve in tumorgenesis of CRC (Sethi et al., 2008; Kantor and Giovannucci, 2015).

\section{Smoking}

With more than 60 carcinogens are present in tobacco, cigarette smoking has been estimated to cause death for more than 500,000 people in 2008 and will be responsible for the death of more than $8,000,000$ by 2030 (Derry et al., 2013). The positive relation between smoking and cancer was identified in 1964 as the primary cause of lung cancer (Anand et al., 2008). Since then, a wide range of malignancies is significantly associated with tobacco consumption (Petti, 2009). The classic studies did not classify smoking as a risk factor for CRC, most likely because the long period of time between exposure and cancer formation (Chan and Giovannucci, 2010). However, recent studies have shown that tobacco use has been consistently associated with an increased risk 
of colorectal adenoma; the time required for this connection is shorter than CRC. Although, it is estimated that approximately $20 \%$ of CRC cases can be attributed to tobacco exposure (Derry et al., 2013; Yang et al., 2015).

Moreover, the risk of tobacco use is vary among the smokers, people who smoking for at least 20 years was associated with a26\% increase in the risk of CRC, compared with nonsmokers, and smoking $20 \mathrm{~g}$ tobacco or more daily was associated with a 30\% increase in CRC risk. Smoking for more than 30 years, or more than $20 \mathrm{~g}$ tobacco daily, was positively associated with a $48 \%$ increase in the risk of CRC (Hansen et al., 2013). In view of gender susceptibility, a study has found that female smoker is more vulnerable to CRC than males (Parajuli et al., 2013). Undoubtedly, tobacco has a broad spectrum of carcinogenic compounds which can easily penetrate the alimentary tract or the circulatory systems, the most important are tobacco-specific nitrosamines, such as 4-(methylnitrosamino)-1-(3-pyridyl)-1butanone (NNK), N-nitrosonornicotine (NNN) and polycyclic aromatic hydrocarbons (PAH) (Petti, 2009). These toxic and carcinogenic substances induce CRC pathogenesis through several possible mechanisms, including the formation of DNA adducts and induce free radicals which promote inflammation and initiate tumorgenesis. Another mechanism may exist when nicotine activities nicotinic acetylcholine receptors on cancer cells and induce the release of growth factors such as vascular endothelial growth factor (VEGF) into tumor microenvironment, which can increase tumor angiogenesis and therefore promote tumor growth (Li et al., 2014; Zhao et al., 2014).

\section{Obesity}

According to WHO, obesity and overweight are described as excessive or abnormal fat accumulation in adipose tissue that may affect the health status. Obesity or overweight is also defined by WHO and Center for Disease Control (CDC) as those who has a body mass index (BMI, weight/ (height in $\left.\mathrm{m}^{2}{ }^{2}\right) \geq$ $25 \mathrm{~kg} / \mathrm{m}^{2}$, overweight individuals have a BMI $\geq 30 \mathrm{~kg} / \mathrm{m}^{2}$ (Derry et al., 2013; Vucenik and Stains, 2012). Increased modernization and a Westernized diet system with less physical activity and more adoption to unhealthy lifestyle have been associated with increased prevalence of obesity worldwide. Globally, overweight is the fifth leading risk for all death cases, accounting for at least 2.8 million adult deaths annually (Bardou et al., 2013). Many studies have indicated that obesity play an essential roles in the promotion of several malignances, such as breast (Kruk, 2014), prostate (Nomura, 2015), liver (Vanni and Bugianesi, 2014), head and neck (Tan et al., 2015), pancreas (Wang et al., 2015) and lung (Rivera et al., 2015). In addition, epidemiological data suggest that obesity is strongly associated with an increased risk of CRC; it is estimated that obesity responsible for 30-70\% increased the risk of CRC in men, with less association in women (Bardou et al., 2013).Previous systematic review in this regard has indicated the incidence of CRC with high obese prevalence. Compared with BMI $<23.0 \mathrm{~kg} \mathrm{~m}^{-2}$, BMI of 23.0-24.9, 25.0-27.4, 27.5-29.9 and $\geq 30.0 \mathrm{~kg} \mathrm{~m}^{-2}$ were associated with $14 \%, 19 \%, 24 \%$ and $41 \%$ increased risks of CRC, respectively, With clear sex-specific differences (Ning et al., 2010). Obesity is connected with a broad range of metabolic changes, and therefore it is difficult to elucidate one single mechanism to be responsible for all obesity-associated cancers. However, exciting evidences provided logical explanation for the underlying mechanism linking obesity with CRC including: modification in levels of adipocytokines and insulin resistance, directly responsible for chronic positive energy balance, which leads to systematic secretion of various neurochemicals factors such as, insulinlike growth factor 1 (IGF-1), Tumor Necrosis Factor-alpha (TNF- $\alpha$ ) Interleukins (IL). Additionally, hyperglycemia has been found to activate NF- $\mathrm{kB}$, which may link obesity with tumorgenesis (Bardou et al., 2013; Durko and Malecka-Panas, 2014; Liu and Yang, 2015). Most importantly, the common factor between obesity and cancer is inflammation, which also relies at the heart of many other diseases (Dahham et al., 2015 b).

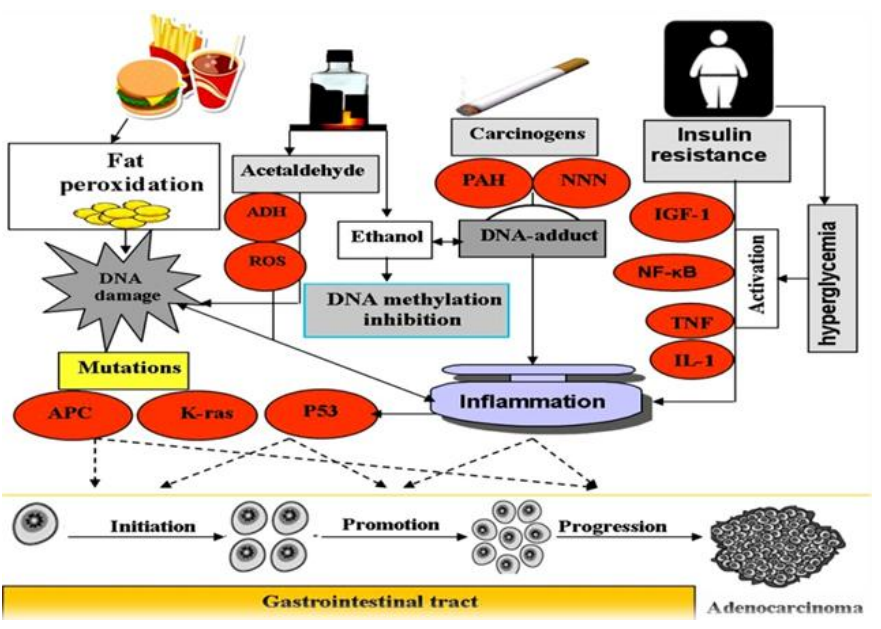

Fig. 2: Effect of lifestyle factors including Diet, Alcohol, smoking and obesity on growth and development of colorectal carcinogenesis

\section{Role of nutritional components in CRC prevention}

In contrast to the unhealthy dietary pattern which includes excessive intake of read and process meat, fat, salt, and sugar. Healthy food and their bioactive constituents have long been known to influence and improve human health(Crowe and Allison, 2015). Although, the healthy diet is an essential element that keeps the basic physiological process functioning properly within the body. In this regards, the American cancer society (ACS) has recommended an intake of 5-10 servings of fruits and vegetables per day and reduce the consumption of refined grains, sugar, fat and red meat (Derry et al., 2013).

Prevention of CRC and its precursor condition via some naturally occurring substances or compounds offers an applicable, acceptable, and accessible basis for CRC control and management. During the last three decades, accumulating evidence from observational studies, epidemiological data and randomized trials have suggests that fruits and vegetables, which is rich in phytochemicals components protect the initiation of CRC (Norat et al., 2014; Nunez-Sanchez et al., 2015).Epidemiological studies 
have suggested that the Mediterranean dietary pattern, which includes consumption of fruits, olive oils and fish is associated with low risk of CRC (Sofi et al., 2014), such dietary system appears to prevent about $25 \%$ of CRC (La Vecchia, 2009). However, there are several nutritional sources have a potential effect against CRC development, including:

\section{Fruits}

Fruits are one of the oldest forms of food, and they have not changed much throughout the history of man (Dahham et al., 2010). It is well established that consumption of a certain type of fruit which contains high amount of fiber, folate, vitamins, minerals and antioxidants can act as a chemo-preventive agents against CRC (Song et al., 2015). Studies on pomegranate and its bioactive products have yielded contestant and significant findings against CRC in vitro, in vivo and in clinical trials (Jaganathan et al., 2014; Molina et al., 2015).Apple and its active componentpolysaccharides has been found to reduce the DNA damage in the distal colon of dimethylhydrazine (DMH)-initiated rats, and also decrease the hyperproliferation of human colon carcinoma cells (HT-29) via induced cell-cycle block in a P53 (Li et al., 2015). Similarly, black raspberry seeds and their active constituents have successfully suppressed the growth of HT-29 cells by up upregulation of $\mathrm{P} 21$ and activation of caspase 3, 8 and 9 (Cho et al., 2015). Another fruit product that has shown chemo-preventive and anticancer potential towards CRC is grape seed extract (GSE) which contain a complex mixture of polyphenols. Recently, GSE has shown the ability to inhibit multiple process such as decrease the chemotactic properties of adipocytes towards CRC cell invasion and display selective antiproliferative and apoptotic activities against CRC cells. (Dinicola et al., 2012; Kumar et al., 2014).From Asian tropical fruits, mangosteen has also found to inhibit HCT-116 and HT-29 cells due to induction of the mitochondrial pathways of apoptosis. The in vivo anti-CRC activity of mangosteen was significantly reduce the tumor volume in nude mice (Aisha et al., 2012; Chang and Yang, 2012). Although, we previously reported that banana extract which is rich in antioxidant components displayed antiproliferative activity against HCT-116 cells (Dahham et al., 2015c). Moreover, a variety of colorful berries, such as strawberries, blueberries, raspberries, blackberries, and bilberries have associated with reduced risk of $\mathrm{CRC}$, these fruits can modulate biomarkers of DNA damage, which may have a potential chemoprotective properties against initiation step of CRC tumorgenesis (Brown et $a l ., 2014)$. Interestingly, a case-control study was recently found that a high consumption of colorful fruit (green, orange, yellow, red, purple and white) is inversely associated with the risk of CRC, and this is attributable to the presence of specific micronutrients and phytochemicals among the edible part of color fruits (Luo et al., 2015).

\section{Vegetables}

Fresh vegetables are an important part of healthy dietary patterns that is rich in phytochemical components, which can promote the healthy functioning of the gastrointestinal tract and prevent several chronic diseases (Grubben et al., 2014). Many epidemiological and observational studies have provided clear evidence that high intake of vegetables was inversely associated with the risk of CRC (Bosetti et al., 2012; Wu et al., 2013). Although, experimental findings has proven the notion of vegetable chemoprevention properties. Research on tomato and its bioactive glycoalkaloid $\alpha$-tomatine has demonstrated in vitro cytotoxic effect against mouse colon cancer CT-26 cells, mediated by apoptosis pathway. In vivo result showed a significant reduction in the tumor growth in the mice by $38 \%$ after 2 weeks (Kim et al., 2015). Another study on onion flavonoids extract showed a promising result, whereby onion's extraction inhibits the proliferation of CRC in new established orthotopic transplant animal model (He et al., 2014). However, among all vegetables, cruciferous vegetables have received much interest due to the unique contents of high glucosinolate which can be metabolized to isothiocyanates (ITCs) and indole-3-carbinol (I3C) by myrosinaseexpressing colonic bacteria. In addition, the multifaceted anticancer properties of ITCs and I3Cs have been investigated in many cell culture and animal model systems (Song et al., 2015). The specific constituents in these vegetables may be responsible for preventing cancer and the mechanisms by which they achieve this activity need for further investigation.

\section{Spices}

Spices are used all over the world to add flavor, color, taste and nutritional value to food. Generally, spices are consumed in the form of dread seed, fruit, bark, and root or vegetable substances (Prasad et al., 2012). Of all spices, turmeric, "the golden spice" has received a great attention from scientific community due to multifunctional activity and phytochemicals diversity. The role of turmeric in CRC prevention has recently examined by using five human colon carcinoma cells, including HCT116, HCT15, HT29, DLD1 and SW480, the ethanol extract of turmeric had significantly inhibited the growth of all cell with an $\mathrm{IC}_{50}$ ranged from 4.3 to $17.4 \mu \mathrm{g} / \mathrm{mL}$ (Dimas et al., 2015). Curcumin, one of the most widely used natural compound isolated from turmeric. Besides curcumin, more than 300 different components, including phenolics and terpenoids, have been identified in turmeric (Gupta et al., 2013).Experimental data

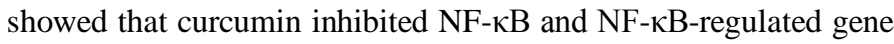
expression in various cancer cell lines. Although, it inhibited inflammation and CRC in animal models (Anand et al., 2008). Moreover, ginger and its active constituents including 6-gingerol and 6-shogaolexert anticancer properties against CRC. The anticancer activity of ginger is attributed to its ability to modulate multiple signaling pathways such as STAT3, MAPK, PI3K, ERK1/2, Akt, TNF- $\alpha$, COX-2, MMP-9, survivin, cIAP-1, XIAP, $\mathrm{Bcl}-2$, caspases, and other cell growth regulatory factors (Prasad and Tyagi, 2015).Black pepper is another interesting spice, which has been consistently used to enhance food taste. Piperine (transtrans isomer of 1-piperoyl piperidine) is an amid alkaloid isolated from black pepper, Piperine has recently showed antiproliferation 
activity against HT-29 cells, obstructed colony formation as well the growth of HT-29 spheroids. Indicating that black pepper and its active principles may be a valuable natural chemopreventive substance against CRC (Yaffe et al., 2014). Furthermore, some active components may also exist in the chemical profile of many other plant species such as $\beta$-caryophyllene, a common sesquiterpene component, which present in enormous essential oils plant, vegetable species, fruits and medicinal herbs, and has been used as food flavoring additive (Calleja et al., 2013). We have recently reported that $\beta$-caryophyllene can suppress metastasis of CRC, induce apoptosis, and inhibit a broad spectrum of microorganisms (Dahham et al., 2014; Dahham et al., 2015 d).

In addition, other nutritional sources such as fish, toad, olive oils, green tea, and truffles and wholegrain foods have also been associated with decreased CRC risk (Dahham et al., 2016; Majid et al., 2016).

\section{CONCLUSION}

Indeed, primary prevention is the best strategy to avoid cancer in general and CRC in particular. This strategy is based on identification and avoidance of environmental or lifestyle factors related to carcinogenesis. Lifestyle choices are like a "doubleedged sword" which can aggravate overall health conditions or result in beneficial effects. Thus, increasing the protective approaches is associated with decreased rates and incidence of CRC. The current review highlights the most common lifestyle factors involved in CRC development. The percentage of CRCrelated deaths attributable to Unhealthy dietary patterns, alcohol intake, smoking and being overweight is as high as 80-90\% worldwide. Another side of the review sheds light on the preventive role of common nutritional components. The fact that certain components (phytochemicals) in fruits, vegetables and spices play a significant role in the prevention of CRC has been supported by numerous lines of studies. Therefore, cancer control strategies must prioritize primary prevention with cancer management and palliative care and implement these approaches into existing health care programs.

Financial support and sponsorship: Nil.

Conflict of Interests: There are no conflicts of interest.

\section{REFERENCES}

Aisha AF, Abu-Salah KM, Ismail Z, Majid AM. In vitro and in vivo anti-colon cancer effects of Garcinia mangostana xanthones extract. BMC complementary and alternative medicine, 2012; 12:104-112

Akin H, Tözün N. Diet, microbiota, and colorectal cancer. Journal of clinical gastroenterology, 2014; 48:67-69.

Anand P, Kunnumakara AB, Sundaram C, Harikumar KB, Tharakan ST, Lai OS, Sung B, Aggarwal BB. Cancer is a preventable disease that requires major lifestyle changes. Pharmaceutical research, 2008; 25:2097-2116.

Azeem S, Gillani SW, Siddiqui A, Jandrajupalli SB, Poh V, Syed SS. Diet and Colorectal Cancer Risk in Asia-a Systematic Review. Asian Pacific journal of cancer prevention: APJCP, 2015; 16:5389.

Bardou M, Barkun AN, Martel M. Obesity and colorectal cancer. Gut, 2013; 62:933-947.
Bastide NM, Pierre FH, Corpet DE. Heme iron from meat and risk of colorectal cancer: a meta-analysis and a review of the mechanisms involved. Cancer prevention research, 2011;4:177-184.

Binefa G, Rodríguez-Moranta F, Teule À, Medina-Hayas M. Colorectal cancer: from prevention to personalized medicine. World $\mathrm{J}$ Gastroenterol, 2014; 20:6786-6808.

Bishehsari F, Mahdavinia M, Vacca M, Malekzadeh R, Mariani-Costantini R. Epidemiological transition of colorectal cancer in developing countries: environmental factors, molecular pathways, and opportunities for prevention. World J Gastroenterol, 2014; 20:6055-6072.

Bogaert J, Prenen H. Molecular genetics of colorectal cancer. Annalsof Gastroenterology, 2013; 27:9.

Brown EM, Latimer C, Allsopp P, Ternan NG, McMullan G, McDougall GJ, Stewart D, Crozier A, Rowland I, Gill CI. In vitro and in vivo models of colorectal cancer: Antigenotoxic activity of berries. Journal of agricultural and food chemistry, 2014; 62:3852-3866.

Bosetti C, Filomeno M, Riso P, Polesel J, Levi F, Talamini R, Montella M, Negri E, Franceschi S, La Vecchia C. Cruciferous vegetables and cancer risk in a network of case-control studies. Annals of Oncology, 2012; 10:604.

Budhathoki S, Iwasaki M, Yamaji T, Sasazuki S, Takachi R, Sakamoto H, Yoshida T, Tsugane S. Dietary heterocyclic amine intake, NAT2 genetic polymorphism, and colorectal adenoma risk: the colorectal adenoma study in Tokyo. Cancer Epidemiology Biomarkers \& Prevention, 2015; 24:613-620.

Calleja MA, Vieites JM, Montero-Meterdez T, Torres MI, Faus MJ, Gil A, Suárez A. The antioxidant effect of $\beta$-caryophyllene protects rat liver from carbon tetrachloride-induced fibrosis by inhibiting hepatic stellate cell activation. British journal of nutrition, 2013; 109:394401.

Chang HF, Yang LL. Gamma-mangostin, a micronutrient of mangosteen fruit, induces apoptosis in human colon cancer cells. Molecules, 2012; 17:8010-8021.

Chan AT, Giovannucci EL. Primary prevention of colorectal cancer. Gastroenterology, 2010; 138:2029-2043.

Chan DS, Lau R, Aune D, Vieira R, Greenwood DC, Kampman E, Norat T. Red and processed meat and colorectal cancer incidence: metaanalysis of prospective studies. PloS one, 2011; 6:e20456.

Crowe KM, Allison D. Evaluating bioactive food components in obesity and cancer prevention. Critical reviews in food science and nutrition, 2015; 55:732-734.

Cho H, Jung H, Lee H, Yi HC, Kwak HK, Hwang KT. Chemopreventive activity of ellagitannins and their derivatives from black raspberry seeds on HT-29 colon cancer cells. Food \& function, 2015; 6:1675-1683.

Clarke JM, Lockett T. Primary prevention of colorectal cancer. InCancer Forum, 2014 38:1-6.

Dahham SS, Ali MN, Tabassum H, Khan M. Studies on antibacterial and antifungal activity of pomegranate (PunicagranatumL.). Am. Eurasian J. Agric. Environ. Sci. 2010; 9:273-281.

Dahham SS, Ahamed MB, Saghir SM, Alsuede FS, Iqbal MA, Majid AM. Bioactive essential oils from Aquilariacrassna for cancer prevention and treatment. Glob. J. Adv. Pure Appl. Sci, 2014;4:2631.

Dahham SS, Tabana YM, Hassan LE, Ahamed MB, Majid AS, Majid AM. In vitro antimetastatic activity of Agarwood (Aquilariacrassna) essential oils against pancreatic cancer cells. Alexandria Journal of Medicine, 2015a; 52: 141-150

Dahham SS,Tabana YM,Ahamed MB,Majid AM.In vivo antiinflammatory activity of $\beta$-caryophyllene, evaluated by molecular imaging. Molecules \& Medicinal Chemistry, 2015b;1:1-6.

Dahham SS, Agha MT, Tabana YM, Majid AM.Antioxidant Activities and Anticancer Screening of Extracts from Banana Fruit (Musa sapientum).Academic Journal of Cancer Research, 2015c;8: 28-34.

Dahham SS, Tabana YM, Iqbal MA, Ahamed MB, Ezzat MO, Majid AS, Majid AM. The Anticancer, Antioxidant and Antimicrobial Properties of the Sesquiterpene $\beta$-Caryophyllene from the Essential Oil of Aquilariacrassna. Molecules, 2015; 20:11808-11829.

Dahham SS, Hew CS, Jaafar I, Gam LH. The Protein Profiling of Asian Giant Toad Skin Secretions And Their Antimicrobial Activity. 
International Journal of Pharmacy and Pharmaceutical Sciences, 2016; 8:88-95.

Derry MM, Raina K, Agarwal C, Agarwal R. Identifying molecular targets of lifestyle modifications in colon cancer prevention. Front Oncol, 2013;3:119.

Dimas K, Tsimplouli C, Houchen C, Pantazis P, Sakellaridis N, Tsangaris GT, Ramanujam RP. An Ethanol Extract of Hawaiian Turmeric: Extensive In Vitro Anticancer Activity Against Human Colon Cancer Cells. Alternative therapies in health and medicine, 2015; 21:46-54.

Dinicola S, Cucina A, Pasqualato A, D'Anselmi F, Proietti S, Lisi E, Pasqua G, Antonacci D, Bizzarri M. Antiproliferative and apoptotic effects triggered by grape seed extract (GSE) versus epigallocatechin and procyanidins on colon cancer cell lines. International journal of molecular sciences,2012; 13:651-664.

Dow LE, O'Rourke KP, Simon J, Tschaharganeh DF, van Es $\mathrm{JH}$, Clevers H, Lowe SW. Apc restoration promotes cellular differentiation and reestablishes crypt homeostasis in colorectal cancer. Cell, 2015; 161:1539-1552.

Durko L, Malecka-Panas E. Lifestyle modifications and colorectal cancer. Current colorectal cancer reports, 2014; 10:45-54.

Ferlay J, Steliarova-Foucher E, Lortet-Tieulent J, Rosso S, Coebergh JW, Comber H, Forman D, Bray F. Cancer incidence and mortality patterns in Europe: estimates for 40 countries in 2012. European journal of cancer, $2013 ; 49: 1374-1403$.

Giovannucci E. Modifiable risk factors for colon cancer. Gastroenterology Clinics of North America, 2002; 31:925-943.

Goel S, Huang J, Klampfer L. K-ras, intestinal homeostasis and colon cancer. Current clinical pharmacology, 2015; 10:73-81.

Guéraud F, Taché S, Steghens JP, Milkovic L, Borovic-Sunjic S, Zarkovic N, Gaultier E, Naud N, Héliès-Toussaint C, Pierre F, Priymenko N. Dietary polyunsaturated fatty acids and heme iron induce oxidative stress biomarkers and a cancer promoting environment in the colon of rats. Free Radical Biology and Medicine, 2015;83:192-200

Gupta SC, Kismali G, Aggarwal BB. Curcumin, a component of turmeric: from farm to pharmacy. Biofactors, 2013;3:2-13.

Grubben G, Klaver W, Nono-Womdim R, Everaarts A, Fondio L, Nugteren JA, Corrado M. Vegetables to combat the hidden hunger in Africa. Chronica Horticulturae, 2014;54:24-32.

Haas SL, Ye W, Löhr JM. Alcohol consumption and digestive tract cancer. Current Opinion in Clinical Nutrition \& Metabolic Care, 2012; 15:457-467.

Haggar FA, Boushey RP. Colorectal cancer epidemiology: incidence, mortality, survival, and risk factors. Clinics in colon and rectal surgery, $2009 ; 22: 191$.

Hansen RD, Albieri V, Tjønneland A, Overvad K, Andersen KK, Raaschou-Nielsen O. Effects of smoking and antioxidant micronutrients on risk of colorectal cancer. Clinical Gastroenterology and Hepatology, 2013;11:406-415.

He Y, Jin H, Gong W, Zhang C, Zhou A. Effect of onion flavonoids on colorectal cancer with hyperlipidemia: an in vivo study. OncoTargets and therapy, 2014;7:101.

Jaganathan SK, Vellayappan MV, Narasimhan G, Supriyanto E. Role of pomegranate and citrus fruit juices in colon cancer prevention. World J Gastroenterol, 2014; 20:4618-4625.

Kantor ED, Giovannucci E. Adolescent Obesity and Inflammation in Relation to Colorectal Cancer Risk: Recent Findings and Future Implications. Childhood Obesity, 2015a;11:335-337.

Kantor ED, Giovannucci EL. Gene-diet interactions and their impact on colorectal cancer risk. Current nutrition reports, 2015b;4:13-21.

Keku TO, Dulal S, Deveaux A, Jovov B, Han X.The gastrointestinal microbiota and colorectal cancer. American Journal of Physiology-Gastrointestinal and Liver Physiology, 2015; 308:351-363.

Key TJ, Schatzkin A, Willett WC, Allen NE, Spencer EA, Travis RC. Diet, nutrition and the prevention of cancer. Public health nutrition, 2004;7:187-200.

Kim SP, Nam SH, Friedman M. The tomato glycoalkaloid $\alpha$ tomatine induces caspase-independent cell death in mouse colon cancer CT-26 cells and transplanted tumors in mice. Journal of agricultural and food chemistry, 2015; 63:1142-1150.
Knudson AG. Two genetic hits (more or less) to cancer. Nature Reviews Cancer, 2001; 1: 157-162.

Kumar S, Kumar D, Raina K, Agarwal R, Agarwal C. Grape seed extract impairs adipocyte-colorectal cancer cell interaction and decreases adipocyte-driven colon cancer stem colonosphere formation. Cancer Research, 2014; 74:4116.

Kruk J. Lifestyle components and primary breast cancer prevention. Asian Pac J Cancer Prev, 2014; 15:10543-10555.

La Vecchia C. Association between Mediterranean dietary patterns and cancer risk. Nutrition reviews, 2009;67:126-129.

Li LF, Chan RL, Lu L, Shen J, Zhang L, Wu WK, Wang L, Hu $\mathrm{T}$, Li MX, Cho CH. Cigarette smoking and gastrointestinal diseases: The causal relationship and underlying molecular mechanisms (Review) International journal of molecular medicine, 2014; 34:372-380.

Li YH, Niu YB, Sun Y, Zhang F, Liu CX, Fan L, Mei QB. Role of phytochemicals in colorectal cancer prevention. World journal of gastroenterology: WJG, 2015;21:9262.

Liu L, Zhuang W, Wang RQ, Mukherjee R, Xiao SM, Chen Z, Wu XT, Zhou Y, Zhang HY. Is dietary fat associated with the risk of colorectal cancer? A meta-analysis of 13 prospective cohort studies. European journal of nutrition, 2011;50:173-1784.

Liu Z, Yang Y. Inflammation driven activation of Wnt pathway: A potential mechanism responsible for obesity-associated colorectal cancer. Obes Res Open J, 2015;1:10-15.

López PJ, Albero JS, Rodríguez-Montes JA. Primary and secondary prevention of colorectal cancer.Clinical medicine insights. Gastroenterology, 2014;7:33.

Luo WP, Fang YJ, Lu MS, Zhong X, Chen YM, Zhang CX. High consumption of vegetable and fruit colour groups is inversely associated with the risk of colorectal cancer: a case-control study. British Journal of Nutrition, 2015;113:1129-1138.

Majid AM, Dahham SS, Al-Rawi SS, Ibrahim AH, Majid AS. Antioxidant, anticancer, apoptosis properties and chemical composition of black truffle Terfeziaclaveryi. Saudi Journal of Biological Sciences, 2016;22.

Martínez ME. Primary prevention of colorectal cancer: lifestyle, nutrition, exercise. InTumor Prevention and Genetics III,Springer Berlin Heidelberg,2005; 177-211.

Moore MA, Sobue T. Strategies for cancer control on an organsite basis. Asian Pac J Cancer Prev, 2010;11:149-164.

Molina AR, Vargas T, Molina S, Sánchez J, Martínez-Romero J, González-Vallinas M, Martín-Hernández R, Sánchez-Martínez R, de Cedrón MG, Dávalos A, Calani L. The ellagic acid derivative 4, 4'-di-Omethylellagic acid efficiently inhibits colon cancer cell growth through a mechanism involving WNT16. Journal of Pharmacology and Experimental Therapeutics, 2015;353:433-444.

Nesbeth PD, Pfalzer A, Iyer L, Parnell L, Liu Z, Mason J, Crott J. Impact of Diet and Genetic Induced Obesity on the Stool Metabolome of Tumor Prone Mice. The FASEB Journal, 2015;29:394-398.

Ning Y, Wang L, Giovannucci EL. A quantitative analysis of body mass index and colorectal cancer: findings from 56 observational studies. Obesity Reviews, 2010;11:19-30.

Nomura AM. Body size and prostate cancer. Epidemiologic reviews, 2015;23:126-131.

Núñez-Sánchez MA, González-Sarrías A, Romo-Vaquero M, García-Villalba R, Selma MV, Tomás-Barberán FA, García-Conesa MT, Espín JC. Dietary phenolics against colorectal cancer-From promising preclinical results to poor translation into clinical trials: Pitfalls and future needs. Molecular nutrition \& food research, 2015;59:12741291.

Norat T, Aune D, Chan D, Romaguera D. Fruits and vegetables: updating the epidemiologic evidence for the WCRF/AICR lifestyle recommendations for cancer prevention. InAdvances in nutrition and cancer, 2014; 35-50

Omar ZA, Ali ZM, Tamin NS. Malaysian Cancer StatisticsData and Figure, Peninsular Malaysia 2006. National cancer registry, ministry of health Malaysia, 2006.

Parajuli R, Bjerkaas E, Tverdal A, Selmer R, Le Marchand L, Weiderpass E, Gram IT. The increased risk of colon cancer due to 
cigarette smoking may be greater in women than men. Cancer Epidemiology Biomarkers \& Prevention, 2013;22:862-871.

Petti S. Lifestyle risk factors for oral cancer. Oral oncology, 2009; 45: 340-350

Prasad S, Gupta SC, Aggarwal BB. Micronutrients and cancer: Add spice to your life. InNutrition, Diet and Cancer, 2012; 23-48.

Pino MS, Chung DC.The chromosomal instability pathway in colon cancer. Gastroenterology, 2010;138:2059-2072.

Prasad S, Tyagi AK. Ginger and its constituents: role in prevention and treatment of gastrointestinal cancer. Gastroenterology research and practice, 2015.

Rajagopalan H, Nowak MA, Vogelstein B, Lengauer C. The significance of unstable chromosomes in colorectal cancer. Nature reviews cancer, 2003;3:695-701

Rehm J, Shield KD. Alcohol and mortality.Global alcoholattributable deaths from cancer, liver cirrhosis, and injury in 2010. Alcohol Res, 2013;35:174-183.

Rivera C, Pecuchet N, Wermert D, Pricopi C, Le PimpecBarthes F, Riquet M, Fabre E. [Obesity and lung cancer: incidence and repercussions on epidemiology, pathology and treatments]. Revue de pneumologie Clinique, 2015; 71:37-43.

Santarelli RL, Pierre F, Corpet DE. Processed meat and colorectal cancer: a review of epidemiologic and experimental evidence. Nutrition and cancer, 2008; 60:131-144.

Sethi G, Sung B, Aggarwal BB. Nuclear factor- $\kappa B$ activation: from bench to bedside. Experimental Biology and Medicine, 2008;233:2131.

Seitz HK, Becker P. Alcohol metabolism and cancer risk. Alcohol Research and Health, 2007;30:38.

Sofi F, Macchi C, Abbate R, Gensini GF, Casini A. Mediterranean diet and health status: an updated meta-analysis and a proposal for a literature-based adherence score. Public health nutrition, 2014; 17:2769-2782.

Song M, Garrett WS, Chan AT. Nutrients, foods, and colorectal cancer prevention. Gastroenterology, 2015; 148:1244-1260.

Sosa V, Moliné T, Somoza R, Paciucci R, Kondoh H, LLeonart ME. Oxidative stress and cancer: an overview. Ageing research reviews, 2013; 12:376-390.

Sung JJ, Lau JY, Goh KL, Leung WK, Asia Pacific Working Group on Colorectal Cancer.Increasing incidence of colorectal cancer in Asia: implications for screening. The lancet oncology, 2005;6:871-876.

Tan X, Nelson HH, Langevin SM, McClean M, Marsit CJ, Waterboer T, Pawlita M, Kelsey KT, Michaud DS. Obesity and head and neck cancer risk and survival by human papillomavirus serology. Cancer Causes \& Control, 2015;2:111-119.

Theodoratou E, Farrington SM, Tenesa A, McNeill G, Cetnarskyj R, Korakakis E, Din FV, Porteous ME, Dunlop MG, Campbell H. Associations between dietary and lifestyle risk factors and colorectal cancer in the Scottish population. European Journal of Cancer Prevention, 2014; $23: 8-17$.
Tuyns A J. Epidemiology of alcohol and cancer. Cancer research, 1979;39: 2840-2843.

Vanni E, Bugianesi E. Obesity and liver cancer. Clinics in liver disease, 2014;18:191-203.

Vargas AJ, Thompson PA. Diet and nutrient factors in colorectal cancer risk. Nutrition in Clinical Practice, 2012;27:613-623.

Vucenik I, Stains JP. Obesity and cancer risk: evidence, mechanisms, and recommendations. Annals of the New York Academy of Sciences, 2012;1271:37-43.

Wang $\mathrm{H}$, Maitra A, Wang $\mathrm{H}$. Obesity, intrapancreatic fatty infiltration, and pancreatic cancer. Clinical Cancer Research, 2015; 21 : 3369-3371.

Wells BG, DiPiro CV, DiPiro JT, Schwinghammer TL. Pharmacotherapy Handbook 7th Edition,2009; McGraw-Hill Companies.

Wu QJ, Yang Y, Vogtmann E, Wang J, Han LH, Li HL, Xiang YB. Cruciferous vegetables intake and the risk of colorectal cancer: a meta-analysis of observational studies. Annals of oncology, 2013;24: 1079-1087.

Yaffe PB, Power Coombs MR, Doucette CD, Walsh M, Hoskin DW. Piperine, an alkaloid from black pepper, inhibits growth of human colon cancer cells via G1 arrest and apoptosis triggered by endoplasmic reticulum stress. Molecular carcinogenesis, 2015;54:1070-1085.

Yang B, Jacobs EJ, Gapstur SM, Stevens V, Campbell PT. Active smoking and mortality among colorectal cancer survivors: the Cancer Prevention Study II nutrition cohort. Journal of Clinical Oncology, 2015;33:885-893.

Zeichner SB, Raj N, Cusnir M, Francavilla M, Hirzel A. A de novo germline APC mutation (3927del5) in a patient with familial adenomatous polyposis: case report and literature review. Clinical Medicine Insights. Oncology, $2012 ; 6: 315$.

Zhao Y, Zhou W, Xue L, Zhang W, Zhan Q. Nicotine activates YAP1 through nAChRs mediated signaling in esophageal squamous cell cancer (ESCC). PloS one, 2014; 9:e90836.

Zheng W, Lee SA. Well-done meat intake, heterocyclic amine exposure, and cancer risk. Nutrition and cancer, 2009; 61:437-446.

\section{How to cite this article:}

Dahham SS, Majid AMA. The Impact of Life Style and Nutritional Components in Primary Prevention of Colorectal Cancer. J App Pharm Sci, 2016; 6 (09): 237-244. 